\title{
DETECCIÓN DE ESTUDIANTES EN RIESGO ACADÉMICO EN EL INSTITUTO TECNOLÓGICO DE COSTA RICA
}

\author{
Edgar Guillén Sánchez \\ Sonia Chinchilla Brenes \\ Departamento de Orientación y Psicología \\ Instituto Tecnológico de Costa Rica
}

Recibido 30-VIII-2004 • Aceptado 7-IX-2004

\begin{abstract}
Resumen: En la presente investigación se practican análisis estadísticos para derivar una ecuación que permita detectar a los estudiantes en riesgo de fracaso académico en el ITCR. Se trabajó con los estudiantes que ingresaron el primer semestre de 1995 a programas de bachillerato bajo la modalidad semestral. Como variable dependiente se manejó la trayectoria seguida por el estudiante a lo largo de siete años (hasta marzo del 2002): Deserción formal; Deserción el primer semestre; Deserción el segundo semestre; Deserción en un semestre posterior; Aún matriculado; Graduado. Como variables independientes se incluyeron el Puntaje de Admisión y sus componentes (Cuarto Ciclo, puntajes en las partes verbal y matemática de la Prueba de Aptitud Académica), Colegio de procedencia (tipo de jornada, tipo de financiamiento y modalidad), Zona geográfica de procedencia; indicadores de rendimiento académico durante el primer semestre; Sexo del estudiante; Carrera en que se matriculó el estudiante. Una ecuación de regresión logística permite clasificar correctamente al 79.9\% de los estudiantes en las categorías de GraduadoNo Graduado. En ella se incluyen indicadores de rendimiento académico durante el primer semestre $y$ Carrera en que se matriculó el estudiante.
\end{abstract}

Palabras clave: Educación superior, rendimiento académico, graduación, riesgo académico.

\section{Justificación}

El rendimiento académico es un fenómeno complejo que suele abordarse en las universidades desde distintos indicadores. Con frecuencia se consideran las calificaciones promedio obtenidas en distintos períodos de la estancia en la universidad, tasas de aprobación de materias y créditos, tasas de retención-deserción, tasas de graduación, períodos de graduación respecto de planes de estudio.

Los resultados en Rendimiento Académico (RA) exhibidos por el ITCR, aunque superiores a los resultados promedio exhibidos por las universidades estatales costarricenses en lo que a deserción y graduación se refiere, son inferiores en cuanto a proporción de materias aprobadas, repitencia y proporción de estudiantes con promedios inferiores a 70 (CONARE, 2000). Además son inferiores a los exhibidos por universidades de otras latitudes y están muy lejos de los exhibidos por universidades prestigiosas de otras latitudes (Colorado Commission on Higher Education, 1991, p. 37-38; Oregon State System of Higher Education, 1994, p. 2,1314; University System of Georgia, 1994, 


\begin{abstract}
This study presents a statistical analysis conducted to determine a model which detects students at risk of academic failure at the Costa Rica Institute of Technology. The population is composed of students who were admitted to undergraduate programs in 1995. The dependent variable was the students' performance for seven years: drop-outs in the first semester, drop-outs in the second semester, drop-outs in any other semester, students currently registered and graduate students. The independent variables were: the Institute's entrance examination score and its components (High School, Math and Oral Components of the Academic Aptitude Test), type of high school (private or public, academic, technical or agricultural) geographic area, academic achievement indicators during the first semester, gender and major. A Logistic Regression Analysis model was used for an accurate classification of the $79.9 \%$ of the students in the categories of undergraduate and graduate. The model includes indicators of both academic performance and the number credits obtained in the students' majors.
\end{abstract}

Key words: Higher Education, academic achievement, graduation figures students at risk of academic failure. p. 7-9, 29; Illinois State Board of Higher Education, 1996, p. 5).

Las bajas tasas de aprobación en asignaturas básicas (Matemática, Física y Química), la repitencia, la deserción y una tasa de graduación cercana a un tercio de la población que ingresa, no tienen por qué perpetuarse como una fatalidad. Se sabe de muchos programas diseñados para enfrentar esta situación que informan de resultados positivos en términos de calificaciones promedio y de tasas de retención y graduación. (Dale, P.M., 1995; University System of Georgia, 1994; New York State Education Department, Bureau of Higher Education Opportunity Programs (HEOP), 1993; Starke. M.C., 1994; Wilkie, C., 1994). Estos programas típicamente detectan a los estudiantes en riesgo de abandonar la universidad y les ofrecen apoyo en distintas áreas, desde cursos y seminarios de técnicas de estudio, organización del tiempo, habilidades interpersonales, integración a la universidad, tutorías, consejería vocacional y psicológica, hasta cursos remediales y becas.

En el ITCR se ha iniciado un programa de este tipo, uno de cuyos insumos es detectar, en lo posible de forma temprana, a los estudiantes en riesgo de ver convertida en fracaso su experiencia universitaria. A esto apunta la investigación Detección de estudiantes en riesgo académico ${ }^{1}$, algunos de cuyos resultados se refieren en el presente artículo.

\section{¿Cómo detectar a los estudiantes en riesgo académico?}

Pasamos revista a informes y artículos que refieren programas de universidades norteamericanas, orientados a apoyar estudiantes en riesgo académico porque interesa conocer qué variables utilizan para tal detección y, cuándo es pertinente, la metodología y técnicas utilizadas.

El HEOP (Higher Education Opportunity Program) está dirigido a estudiantes en desventaja educativa y económica. 
La desventaja económica se operacionaliza en función del ingreso familiar o de la carencia de apoyo económico familiar al estudiante. La desventaja educativa se operacionaliza en términos de si el estudiante es inadmisible, según los estándares normales, a la carrera que quiso ingresar en un campus determinado. Se trata en general de estudiantes con bajos promedios en secundaria y bajas notas en la parte verbal y/o matemática del examen de admisión (New York State Education Department, 1993, p. 12).

Según el estudio de "educación de desarrollo" (developmental education) en Pennsylvania, la población meta de este tipo de educación son estudiantes de bajos ingresos quienes usualmente están subpreparados académicamente, estudiantes con admisión especial, estudiantes con problemas de aprendizaje (learning disabled students), y estudiantes que tienen el inglés como segunda lengua (Wilkie, 1994, p. 16).

Según el estudio de retención y graduación en el sistema universitario de Georgia, todas las universidades cuentan con un programa de estudios de desarrollo (developmental studies). Los estudiantes con deficiencias en el curriculum de preparatoria y los que tienen puntajes de admisión por debajo de los mínimos institucionales deben hacer un examen de ubicación. Según sus resultados pueden ser remitidos a recibir instrucción en composición, lectura o matemática (University System of Georgia, 1994, p. 34). También se ofrecen programas para apoyar a estudiantes provenientes de minorías étnicas, a estudiantes de bajos ingresos y a estudiantes con discapacidades físicas y de aprendizaje (learning disabled).

El programa Horizons de la Universidad de Purdue cubre estudiantes universitarios de primera generación (hijos de padres no universitarios), de bajos ingresos o con discapacidades físicas. Estos estudiantes además resultan tener bajos puntajes de admisión, por lo que se consideran estudiantes con una preparación académica inferior a los estudiantes regulares de la universidad (Dale, 1995).

Kezar (2000) en su revisión de programas de verano de preingreso, asegura que la población a que sirven estos programas varía ampliamente, destacándose las minorías, estudiantes de bajos ingresos, estudiantes con alguna discapacidad y estudiantes que no alcanzan los mínimos en pruebas de ubicación.

En Ramapo College es obligatoria la participación en el seminario para estudiantes de nuevo ingreso (Starke, 1994).

El programa de éxito estudiantil en Mohawk College, Ontario, aplica un test para detectar estudiantes en "alto riesgo" (Noel/Levitz College Student Inventory) (Grevatt, 1992).

El curso "Psicología del automanejo académico" ofrecido por la West Virginia University, define como estudiantes en alto riesgo a los estudiantes de nuevo ingreso con bajos puntajes en el ACT (American College Testing) o en el SAT (Scholastic Aptitud Test) y/o un promedio de 2,5 o inferior en High School (Clarke, 1992).

Puede verse que el menú de indicadores de riesgo es amplio. Como variables predictoras destacan bajos ingresos económicos, bajos puntajes en la prueba de aptitud académica y/o en pruebas diagnósticas específicas. A nivel estatal los programas de Nueva York y Georgia, que cubren decenas de universidades, utilizan estas variables para definir sus poblaciones meta. El estudio del sistema universitario de Georgia muestra que, por categorías de admisión, los estudiantes mejor preparados muestran tasas de retención superiores a los menos preparados (University System of Geogia, 1994, p. 38). "Las instituciones que admiten estudiantes nuevos con los promedios más altos en el SAT y con los promedios más altos en secundaria, generalmente retienen una mayor proporción de esos estudiantes" (op. cit., p. 3). Lo mismo refiere el sistema estatal de Oregon respecto de las tasas de graduación: 
Se da una clara y consistente relación lineal entre los promedios de secundaria o la prueba de aptitud académica (SAT) y las tasas de graduación de la universidad: cuanto más alto el promedio en secundaria o el puntaje de admisión, más alta la tasa de graduación (Oregon State System of Higher Education, 1994, p. 4).

Debe anotarse que discapacidades físicas o de aprendizaje y pertenencia a minorías étnicas también se emplean como variables predictoras de riesgo académico.

Hasta aquí se han revisado experiencias en las cuales se utilizan variables predictoras para definir estudiantes en riesgo antes de su ingreso a la universidad. En un estudio de otra naturaleza, Huesman y otros (1996), intentaron determinar un modelo de Regresión Logística para predecir persistencia de los estudiantes entre el primer y segundo semestre y entre el primero y segundo año. Incluyeron gran cantidad de variables, desde variables demográficas, actividades extracurriculares, necesidades financieras, actitud de la familia, compromiso con la institución, metas académicas, ajuste del estudiante a la institución, soporte brindado por la universidad, hasta variables académicas (puntajes en el ACT, rango en secundaria, promedio en secundaria, asignaturas cursadas en secundaria, promedio en el primer semestre universitario, proporción de créditos aprobados en el primer semestre y en el segundo semestre).

Para sus propósitos Huesman y sus colaboradores trabajaron con cerca de 3000 estudiantes que ingresaron a la universidad de Iowa en el otoño de 1994. Tomaron parte del ACT (perfil del estudiante) y aplicaron una encuesta, elaborada al efecto, a todos los estudiantes, utilizaron además la información demográfica y académica de los registros universitarios.

Para el modelo de persistencia del primero al segundo semestre excluyeron las variables correspondientes a promedio obtenido en el primer semestre y proporción de créditos aprobados. Para este modelo, de 20 variables incluidas sólo 2 ingresaron: rango en secundaria y participación en actividades atléticas en secundaria. $R=.116$

Para el modelo de persistencia del primero al segundo año de 23 variables ingresaron cuatro: promedio obtenido en el primer semestre universitario, proporción de créditos aprobados en el primer semestre, proporción de créditos aprobados en el segundo semestre, el estudiante percibe que necesita ayuda financiera. $\mathrm{R}=.194$

El modelo para predecir persistencia en el segundo año es mejor que el que pretende predecir persistencia en el segundo semestre. No obstante, aún cuando el porcentaje general de casos clasificados correctamente es 90,2, sólo el 22,6\% de los desertores se identificaron correctamente.

Tómese nota de que el estudio de Huesman y colaboradores incluye el puntaje en el ACT como variable predictora y el rango en el último ciclo de secundaria que usualmente tienen poder predictivo sobre los promedios del primer semestre y del primer año. Para las dicotomías deserción en el primer semestre sólo rango en secundaria se incluye en la ecuación. El estudio señala además que los resultados en el primero y segundos semestres universitarios pueden tener un doble carácter de predictores y de indicadores de éxito-fracaso; mientras otros estudios los toman como indicadores, el que reseñamos los maneja como predictores.

\section{Definición del problema}

¿Con las variables contenidas en los registros institucionales es posible detectar a los estudiantes en riesgo de fracaso académico? ¿Qué poder explicativo tienen esas variables sobre la Trayectoria académica de los estudiantes en el ITCR? ¿Es posible establecer una ecuación para clasificar a los estudiantes en las distintas categorías de su posible trayectoria académica en el ITCR?

Definimos la deserción, la retención y la graduación como los indicadores de éxito- 
fracaso académico, por tanto estas son nuestras variables dependientes. Estas variables a su vez pueden ser manejadas a distintos intervalos de tiempo. Como se sabe que el problema de la deserción es más agudo en los dos primeros semestres se manejan tres categorías de deserción: deserción en el primer semestre, deserción en el segundo semestre y deserción en otro momento. La categoría retención incluye a los estudiantes aún matriculados, no graduados, al momento de realizar los análisis. Se maneja una única categoría de graduación, vale decir, graduado o no graduado al momento de tomar los datos de las bases de datos del Departamento de Admisión y Registro (los análisis se hacen con la cohorte de 1995, los datos se tomaron en marzo de 2002). Estas distintas categorías del devenir en la historia académica de los estudiantes las hemos agrupado en una variable (nuestra variable dependiente) que hemos llamado Trayectoria.

Como variables predictoras o independientes se recurrió a la información disponible en los registros institucionales. De las experiencias revisadas resulta plausible tomar como predictoras tres conjuntos de variables a saber: las asociadas con el Puntaje de Admisión; variables indicadoras de rendimiento académico durante el primer semestre; variables indicadoras de nivel socioeconómico. Se incluyeron además Sexo del estudiante y Adscripción a Carrera. No se nos escapa que igualmente parece recomendable incluir pruebas diagnósticas de problemas de aprendizaje, habilidades cognoscitivas, conocimientos básicos, hábitos de estudio; este tipo de exploración, sin embargo, quedará para un proyecto en el futuro.

Dentro del conjunto de variables asociadas al Puntaje de Admisión se contemplan Puntaje de Admisión, Promedio en Cuarto Ciclo, Puntaje en el Área Matemática de la Prueba de Aptitud Académica, Puntaje en el Área Verbal de la Prueba de Aptitud Académica.
Dentro del conjunto de variables indicadores de rendimiento académico durante el primer semestre se contemplan: Promedio simple de materias con nota $>$ $0^{2}$, Cantidad de créditos abandonados, Cantidad de créditos aprobados, Cantidad de materias cursadas con promedio $>0$, Cantidad de créditos cursados, Proporción de créditos aprobados respecto de cursados y respecto de matriculados ${ }^{3}$, Sexo, Cantidad de créditos retirados, Cantidad de créditos matriculados. Se incluyen además promedios y proporción de créditos aprobados sobre matriculados y cursados en distintos momentos de la historia académica del estudiante para explorar su poder predictivo.

Como variables indicadoras de nivel socioeconómico se contemplan: Colegio de procedencia (diurno-nocturno, oficial-privado-semioficial, académico-vocacionalagropecuario), zona de procedencia (ruralurbano).

\section{Objetivos}

Describir los resultados de Rendimiento Académico de los estudiantes de la cohorte de 1995. En particular: Retención-deserción para el primer y segundo semestre; Deserción posterior al segundo semestre; Retención y Graduación a marzo del 2002.

Explorar el poder explicativo de los conjuntos de variables asociadas con el Puntaje de Admisión, variables indicadoras de rendimiento académico, variables indicadoras de nivel socioeconómico, sobre la Trayectoria académica seguida por el estudiante.

Determinar un modelo de la probable ubicación en las categorías de Trayectoria académica seguida por el estudiante a partir de los conjuntos de variables asociadas con Puntaje de Admisión, variables indicadoras de rendimiento académico, variables indicadoras de nivel socioeconómico. 


\section{Población}

Los 898 estudiantes que ingresaron al ITCR el primer semestre de 1995 a un programa conducente al grado bachiller bajo la modalidad semestral. La ubicación del estudiante en las categorías de Trayectoria se realizó con los resultados académicos a marzo de 2002.

Se escogió la cohorte de 1995 para poder trabajar con graduación como variable dependiente. Esto aún cuando se sabe que la población de estudiantes del Instituto ha estado sufriendo cambios importantes en años recientes, por ejemplo en composición gran área metropolitanazonas rurales, proporción de estudiantes provenientes de colegios privados y semioficiales (CONARE, 1997 y Guillén, 2001).

\section{Resultados}

La Tabla 1 muestra los resultados para la variable Trayectoria según sexo. La primera columna identifica las seis categorías de Trayectoria. Las columnas dos y tres presentan los datos para los hombres y las mujeres, respectivamente.

Veamos en primer lugar los resultados globales de Trayectoria. Cuarenta y siete estudiantes $(5,2 \%)$ formalizaron retiro o congelamiento o se retiraron de hecho sin realizar los trámites correspondientes.

Tabla 1

Trayectoria seguida por el estudiante * Sexo

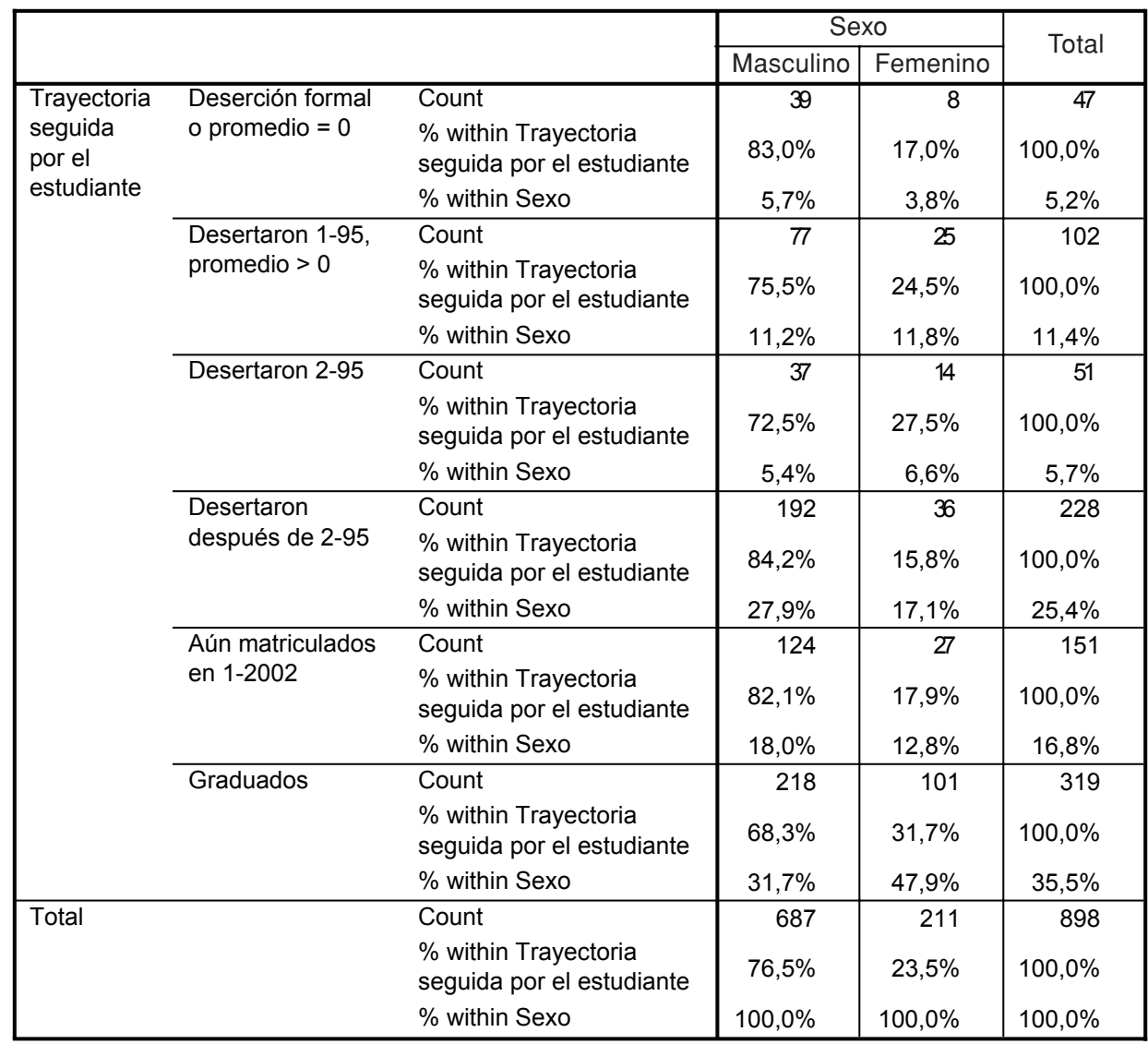


Ciento dos estudiantes $(11,4 \%)$ desertaron el primer semestre y $51(5,7 \%)$ el segundo semestre. Al primer año la deserción acumulada asciende al 22,27\%. Al primer semestre de 2002, siete años después, la deserción alcanza el 47,66\%. 25,4\% de los estudiantes desertaron entre 1996 y 2001. Se corrobora que la deserción es mayor en el primer año de estudios y particularmente en el primer semestre de la vida académica del estudiante.

Ciento cincuenta y un estudiantes $(16,8 \%)$ permanecían matriculados en el primer semestre de 2002 y aún no habían obtenido el bachillerato.

Trescientos diecinueve estudiantes (35,5\%) habían obtenido el bachillerato (tres la licenciatura en agronomía) al primer semestre de 2002. Para efectos de este cuadro los estudiantes graduados no se incluyen dentro de la categoría 'Aún matriculados I Sem 2002', aún cuando algunos de ellos efectivamente continuaban matriculados.

Valga anotar que estos resultados señalan un cambio positivo respecto de los mostrados en el informe de CONA$\mathrm{RE}$ (2000). La deserción en el primer año, incluyendo la deserción formal, es del 24,79\% para la Cohorte de 1990 (Fuente Cuadro 4, CONARE, 2000) en tanto para la cohorte de 1995 es $22,27 \%$. La tasa de graduación reportada por CONARE para la cohorte de 1990 es de 33,3\% en nueve años, en tanto para la cohorte de 1995 es de $35,5 \%$ en siete años.

Repasemos ahora los resultados en Trayectoria por sexo. Se puede ver que para esta cohorte el 23,5\% corresponde a mujeres y el 76,5\% a hombres. Comparada con la cohorte de 1990 (Fuente Cuadro 1 CONARE, 2000) la proporción de mujeres pasa de $22 \%$ a $23,5 \%$. Una ganancia pequeña pero significativa.

Proporcionalmente las mujeres superan a los hombres en deserción durante el primer y segundo semestre, la deserción posterior, sin embargo, es sensiblemente menor entre las mujeres lo mismo que la deserción formal durante el primer semestre.
Es evidente que las mujeres muestran mejores resultados tanto en términos de deserción como en su tasa de graduación. De las mujeres que ingresaron en 1995 el 47,9\% se habían graduado para el primer semestre de 2002, para los hombres el porcentaje correspondiente es $31,7 \%$.

Por razones de espacio no se presentan los resultados por Carrera ni por Carrera-Sexo. Referimos al lector interesado al informe de investigación base del presente artículo. Valga anotar, sin embargo, que se presentan cursos muy diferentes en Trayectoria según Carrera.

\section{Poder explicativo de las variables independientes}

Referimos ahora los resultados de los Análisis de Varianza practicados con los tres conjuntos de variables que se exploraron en la investigación, teniendo Trayectoria como variable dependiente. Por razones de espacio referimos únicamente las tablas con las medidas de asociación (Eta mide la asociación entre una variable nominal y una variable en escala de intervalo), que ofrecen una medida de su poder predictivo.

La Tabla 2 presenta los valores de Eta y Eta Cuadrado para las variables asociadas al Puntaje de Admisión (Puntnorm). Parte Matemática de la Prueba de Aptitud Académica (Notamath). Parte Verbal de la Prueba de Aptitud Académica (Notaverb). Promedio en Cuarto Ciclo de secundaria en las cinco asignaturas que se consideran para estos propósitos (Not4Cicl).

Puede verse que el poder explicativo de Puntaje Normalizado y Cuarto Ciclo sobre Trayectoria seguida por el estudiante (el cuadrado de eta), es realmente reducido: 1,5\% para Puntaje Normalizado, 3,4\% para Cuarto Ciclo. Es claro entonces que las variables asociadas a Admisión, por sí solas, aportan muy poco para predecir la Trayectoria seguida por el estudiante y por ende, para detectar a los estudiantes en riesgo académico. 
Tabla 2

Medidas de Asociación

\begin{tabular}{|l|l|c|}
\hline & Eta & Eta cuadrado \\
\hline puntnorm * Trayectoria &, 123 &, 015 \\
notamath * Trayectoria &, 091 &, 008 \\
notaverb * Trayectoria &, 052 &, 003 \\
not4cicl * Trayectoria &, 185 &, 034 \\
\hline
\end{tabular}

Esto coincide con los resultados de otro estudio (Guillén, 1999), pero no con otros reportes de la literatura especializada (Ramist, 1984; Oregon State System of Higher Education, 1994). Las pruebas de admisión (sean de conocimientos o de aptitud académica) y los resultados en secundaria suelen ser instrumentos utilizados por los programas de apoyo a estudiantes en riesgo académico (Huesman, 1996; Wilkie, 1994; Dale, 1995; New York State Education Department, 1993; Kezar, 2000; Clarke, 1992).

Debe anotarse que los supuestos de normalidad y homogeneidad de las varianzas no se cumplen en todos los casos. Al respecto Cohen \& Cohen (1983, p. 51 s) refiere que el Análisis de Varianza es una técnica robusta que funciona adecuadamente aún con violación de supuestos. No obstante, para aumentar la confianza en los resultados obtenidos se practicaron análisis de varianza no paramétricos, en particular la prueba de Kruskal-Wallis, la más eficiente de las pruebas no paramétricas para $\mathrm{k}$ muestras independientes según Siegel (1958, p. 225). Los resultados (no se presentan) coinciden con los aquí referidos.

Se practicaron pruebas de Chi-Cuadrado entre Trayectoria y Jornada del colegio de procedencia (diurna-nocturna), Tipo de financiamiento del colegio de procedencia (Público, Semi-público, Privado), Modalidad del colegio de procedencia (Académico, Técnico Industrial, Científico, Técnico Comercial). Las pruebas no resultaron estadísticamente significativas. Lo mismo se presentó para la relación Trayectoria - Zona de Procedencia Geográfica (Gran Área Metropolitana - Fuera del GAM).
La carencia de poder explicativo de indicadores de nivel socioeconómico sobre Trayectoria no coincide con las prácticas de los programas de algunas universidades estadounidenses orientados a apoyar a los estudiantes en riesgo académico, para los cuales el nivel socioeconómico suele ser una condición suficiente para ingresar al programa. (Kezar, 2000; Dale, 1995; Wilkie, 1994; New York State Education Department, 1993, University System of Georgia, 1994).

Estos resultados pueden obedecer a que los indicadores de nivel socioeconómico utilizados en esta investigación realmente no reflejen el nivel socioeconómico. En países del tercer mundo esta suele ser una dimensión muy elusiva, al contrario de lo que sucede en países desarrollados, donde los datos de impuesto de la renta (según Hacienda) o la posición en la jerarquía ocupacional junto con el nivel educativo, son indicadores válidos del estatus socioeconómico (Kerbo, 1998).

También pueden obedecer al efecto de superselección que refieren Bourdie y Passeron (1977). Según estos autores los estratos más bajos (en nuestra sociedad los más numerosos), tienen una subrepresentación en el sistema de enseñanza universitaria. Lo contrario ocurre con los estratos altos. De este modo los estudiantes de los estratos bajos han pasado por un proceso de superselección, en tanto su contrapartes no, de ahí que los representantes de los estratos bajos algunas veces hasta pueden superar a sus contrapartes. Según estos autores la comparación no debe hacerse sólo entre quienes acceden a la universidad, también deben considerarse las proporciones de los sectores que quedaron excluidos.

La Tabla 3 presenta los valores de Eta y Eta Cuadrado para los promedios en el primer semestre, segundo semestre, primer año y acumulado en la historia académica del estudiante en relación con Trayectoria.

La Tabla muestra altas correlaciones entre Trayectoria seguida por el estudiante 
y sus calificaciones promedio en distintos momentos de su vida académica, con excepción de Promedio en el 2 semestre que muestra una correlación moderada. Nótese su contraste con las bajas correlaciones exhibidas por las variables asociadas a Puntaje de Admisión.

Tabla 3

Medidas de Asociación

\begin{tabular}{|l|c|c|}
\hline & Eta & Eta cuadrado \\
\hline Promedio simple I semestre * Trayectoria &, 687 &, 472 \\
Promedio simple 2 semestre * Trayectoria &, 533 &, 284 \\
Promedio simple en el primer año * Trayectoria &, 718 &, 516 \\
Promedio Total * Trayectoria &, 782 &, 612 \\
\hline
\end{tabular}

La Tabla 4 presenta la correlación entre la proporción promedio de créditos aprobados respecto de cursados y matriculados en distintos momentos de la trayectoria académica de los estudiantes.

La tabla muestra altas correlaciones entre Trayectoria seguida por el estudiante y sus proporciones promedio de créditos aprobados en distintos momentos de su vida académica, con excepción de los resultados en el segundo semestre que muestra una correlación moderada.

Varios hechos merecen destacarse:

1. Proporción promedio de créditos aprobados tiene un poder explicativo sobre
Trayectoria superior al que tienen las calificaciones promedio, excepto los resultados del segundo semestre.

2. La proporción de créditos aprobados sobre matriculados muestra un poder explicativo levemente superior a proporción de créditos aprobados sobre cursados, para el primer semestre y para la historia académica del estudiante.

3. Los indicadores de Rendimiento Académico elevan su poder predictivo conforme se alargan los períodos sobre los cuales se calculan. Nótese que el promedio al primer año tiene un poder explicativo superior al del primer semestre e inferior al promedio total del período analizado. Lo mismo sucede para las proporciones de créditos aprobados. Esto indica que el Rendimiento Académico con el tiempo consolida su poder explicativo sobre Trayectoria: estudiantes que inicialmente tienen un RA deficiente y superan esta situación, se mantienen en el Instituto y eventualmente se gradúan, lo inverso sucedería con estudiantes que inicialmente muestran un buen RA y luego desertan.

4. $\mathrm{Si}$ bien los indicadores de $\mathrm{RA}$ al primer semestre muestran un poder

Tabla 4

Medidas de Asociación

\begin{tabular}{|c|c|c|}
\hline & Eta & Eta cuadrado \\
\hline \% Créditos Aprobados respecto Cursados, 1-95* Trayectoria & ,638 & ,407 \\
\hline$\%$ Créditos Aprobados respecto Matriculados, $1-95 *$ Trayectoria & ,654 & ,428 \\
\hline$\%$ Créditos Aprobados respecto Cursados, 2-95* Trayectoria &, 520 & 271 \\
\hline$\%$ Créditos Aprobados respecto Matriculados, 2-95* Trayectoria &, 523 & 273 \\
\hline$\%$ Créditos Aprobados respecto Cursados, Año-95 * Trayectoria &, 711 & ,505 \\
\hline $\begin{array}{l}\text { \% Créditos Aprobados respecto Matriculados, Año- } 95 * \\
\text { Trayectoria }\end{array}$ &, 714 & ,509 \\
\hline $\begin{array}{l}\text { Porcentaje créditos aprobados respecto cursados durante el período } \\
\text { analizado * Trayectoria }\end{array}$ & ,809 & ,655 \\
\hline $\begin{array}{l}\% \text { Créditos Aprobados respecto de matriculados durante el período } \\
\text { analizado * Trayectoria }\end{array}$ & ,833 & ,694 \\
\hline Créditos Aprobados, 1-95* Trayectoria & 629 & ,396 \\
\hline
\end{tabular}


explicativo sobre Trayectoria inferior a indicadores de mayor plazo, lo cierto es que ese poder explicativo no es nada despreciable (supera el $40 \%$ de varianza explicada). Los estudiantes que tienen bajas calificaciones en el primer semestre y/o aprueban pocos créditos tienden a abandonar la Institución ese semestre, lo contrario ocurre con los estudiantes que se gradúan.

5. Los indicadores de RA en el primer semestre surgen como potenciales buenos predictores de Trayectoria, toda vez que los conjuntos de variables asociadas a Puntaje de Admisión e Indicadores de Nivel Socioeconómico muestra escaso o nulo poder predictivo. Esto además coincide con los hallazgos de Huesmann (1996). Indicadores de largo plazo no tienen utilidad práctica pues se convierten en la confirmación de una situación consolidada sin valor de pronóstico. En adelante nos concentramos en explorar indicadores de RA en el primer semestre.

\section{Análisis discriminante}

Se practicó un Análisis Discriminante con Trayectoria como variable dependiente. Como variables independientes se incluyeron los siguientes indicadores de RA del primer semestre: Promedio simple de materias con nota $>0$, Cantidad de créditos abandonados, Cantidad de créditos aprobados, Cantidad de materias cursadas con promedio $>0$, Cantidad de créditos cursados, Proporción de créditos aprobados respecto de cursados, Cantidad de créditos aprobados respecto de matriculados, Sexo, Cantidad de créditos retirados, Cantidad de créditos matriculados. Se estipuló el método de inclusión por pasos. Las variables se incluyeron en el orden en que se listan; las dos últimas variables no alcanzaron a entrar en las ecuaciones.

La Tabla 5 da cuenta de la clasificación de los casos en las categorías de Trayectoria a partir de las ecuaciones discriminantes. La proporción de casos correctamente clasificados alcanza el 54,4\%. Puede verse

Tabla 5

Classification Results ${ }^{\mathrm{a}}$

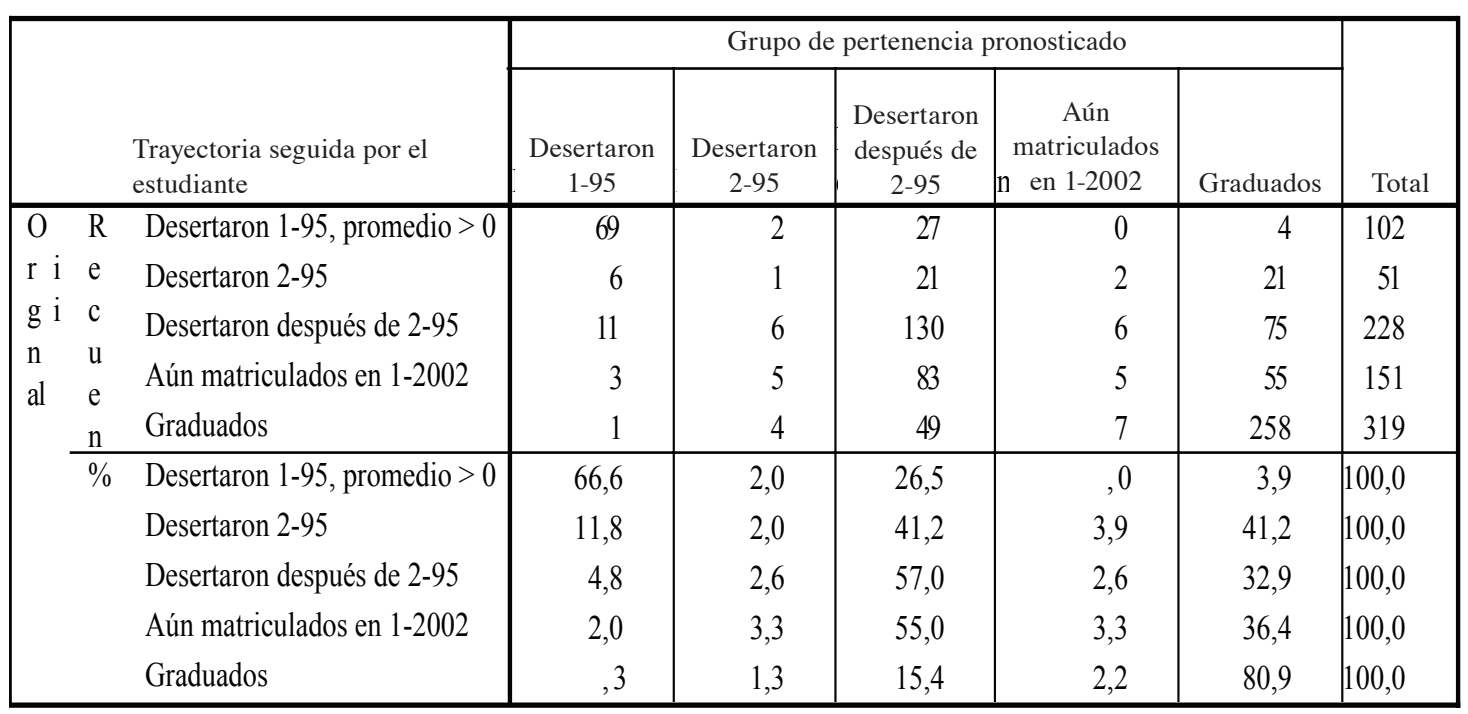

a. Clasificados correctamente el $54,4 \%$ de los casos agrupados originales. 
sin embargo que al interior de las categorías se presenta gran variación en el porcentaje de aciertos: $80,9 \%$ para la categoría Graduados, 2\% para quienes desertaron el segundo semestre.

Estos resultados nos obligan a renunciar a nuestra pretensión de "pronosticar" la ubicación del estudiante en alguna de las categorías de Trayectoria. Señalan además que se obtendría mayor precisión trabajando con dicotomías: Deserta el primer semestre-No deserta el primer semestre, Deserta después del segundo semestre-No deserta después del segundo semestre, Graduado-No Graduado. La dicotomía Deserta el primer semestre, con indicadores de ese semestre no tiene valor práctico. La dicotomía Deserta después del segundo semestre con indicadores del primer semestre ofrece una proporción baja de clasificaciones correctas (remitimos al lector interesado al informe de investigación base del presente artículo). En conformidad con estos resultados orientamos la búsqueda a la exploración de las dicotomía Graduado-No Graduado, con Análisis de Regresión Logística.

\section{Análisis de Regresión Logística con indicadores del primer semestre}

\section{Variable dependiente: Gradua-} do ( 1 = se graduó en el período estudiado -siete años).

Variables independientes: Promedio simple en el primer semestre en asignaturas con nota $>0$ (PROISEM); Número de asignaturas cursadas con nota $>0$; Créditos matriculados el primer semestre; Créditos cursados el primer semestre; Créditos aprobados el primer semestre (CRAPR195); Créditos retirados formalmente el primer semestre; Créditos abandonados el primer semestre (cursados con nota $=0$ ); Créditos aprobados respecto de matriculados el primer semestre; Créditos aprobados respecto de cursados el primer semestre; Escuela a la que fue adscrito el estudiante al ingresar (IDE _ DEPT - variable categórica recodificada con "effects coding"); Sexo del estudiante (variable categórica recodificada como "dummy").

Todas las variables exhiben un puntaje cuya significancia las hace candidatas a ser incluidas en la ecuación.

Número de casos incluidos en el análisis: 841.

Método de inclusión de variables: Inclusión por pasos (Forward: LR).

Con la dicotomía Graduado-No Graduado, la mejor predicción que se puede hacer es que el $62,3 \%$ de los estudiantes no se gradúa en siete años. Con esta predicción, sin embargo, no se clasifica correctamente a ninguno de los estudiantes graduados en ese período.

Las Tablas 6 a 9 nos informan sobre la bondad del ajuste del modelo para predecir la pertenencia de los estudiantes a cada una de las dos categorías de 'Graduado'. La significancia de Chi-cuadrado para el modelo, inferior a ,05, informa que los coeficientes mejoran significativamente la predicción, respecto de la predicción inicial.

El $R$ cuadrado de Nagelkerke, indica que el modelo de Regresión Logística explica el comportamiento de la variable dependiente en un $47 \%$.

La Tabla 8 informa que con el modelo se pasa de un $62,3 \%$ de clasificaciones correctas a un $79,9 \%$. Se clasifica

Tabla 6

Omnibus Tests of Model Coefficients

\begin{tabular}{|ll|c|c|c|}
\hline & & Chi-cuadrado & gl & Sig. \\
\hline Paso 1 & Paso & 271,582 & 1 &, 000 \\
& Bloque & 271,582 & 1 &, 000 \\
& Modelo & 271,582 & 1 &, 000 \\
\hline Paso 2 & Paso & 38,941 & 1 &, 000 \\
& Bloque & 310,523 & 2 &, 000 \\
& Modelo & 310,523 & 2 &, 000 \\
\hline Paso 3 & Paso & 48,700 & 12 &, 000 \\
& Bloque & 359,223 & 14 &, 000 \\
& Modelo & 359,223 & 14 &, 000 \\
\hline
\end{tabular}


Tabla 7

Model Summary

\begin{tabular}{|c|c|c|c|}
\hline Paso & $\begin{array}{c}-2 \log \text { de la } \\
\text { verosimilitud }\end{array}$ & $\begin{array}{l}\text { R cuadrado de } \\
\text { Cox y Snell }\end{array}$ & $\begin{array}{l}\text { R cuadrado de } \\
\text { Nagelkerke }\end{array}$ \\
\hline 1 & $842,815 \quad a$ & ,276 &, 376 \\
\hline 2 & $803,873 \quad b$ & ,309 & , 420 \\
\hline 3 & $755,173 \quad b$ & ,348 & ,473 \\
\hline
\end{tabular}

a. La estimación ha finalizado en el número de iteración 5 porque las estimaciones de los parámetros han cambiado en menos de ,001.

b. La estimación ha finalizado en el número de iteración 6 porque las estimaciones de los parámetros han cambiado en menos de, 001 .

correctamente al $84,2 \%$ de los no graduados y al $72,9 \%$ de los graduados, sin duda una mejora considerable.

La Tabla 9 da cuenta de las 'Variables en la ecuación'. En general es claro que por las intercorrelaciones entre ellas, de ser todas potencialmente capaces de aportar a la explicación de la dependiente, sólo tres permanecen con un nivel significativo: 'Créditos aprobados el primer semestre', 'Promedio en el primer semestre' y 'Escuela a la que fue adscrito el estudiante'.

En virtud de las altas correlaciones entre las variables y a que el método de inclu- sión es muy sensible a estas situaciones, se corrió 10 veces este análisis con muestras del $75 \%$ de los casos para corroborar la estabilidad de la selección de las variables. En todos los casos permanecieron las mismas variables, en dos de ellos se sumó además la variable 'Créditos Aprobados respecto de cursados', en otro caso se sumó la variable 'Créditos Abandonados'. Los porcentajes de clasificaciones correctas se movieron entre $78,6 \%$ y $81,2 \%$. Se incluyeron además los términos de interacciones que no ofrecieron poder explicativo adicional, no se incluyen para no alargar aún más este informe.

Con los resultados en los indicadores de rendimiento académico durante el primer semestre, aplicando este modelo de Regresión Logística, podríamos "predecir" con relativa certeza la ubicación de los estudiantes en una de las categorías de Graduado-No Graduado en siete años. En principio para los estudiantes No Graduados acertaríamos en el $84,2 \%$ de los casos y fallaríamos en el 15,8\%. Para los estudiantes Graduados acertaríamos en el $72,9 \%$ de los casos y fallaríamos en el $27,1 \%$ de los casos. Para nuestros intereses

Tabla 8

Tabla de clasificación ${ }^{c}$

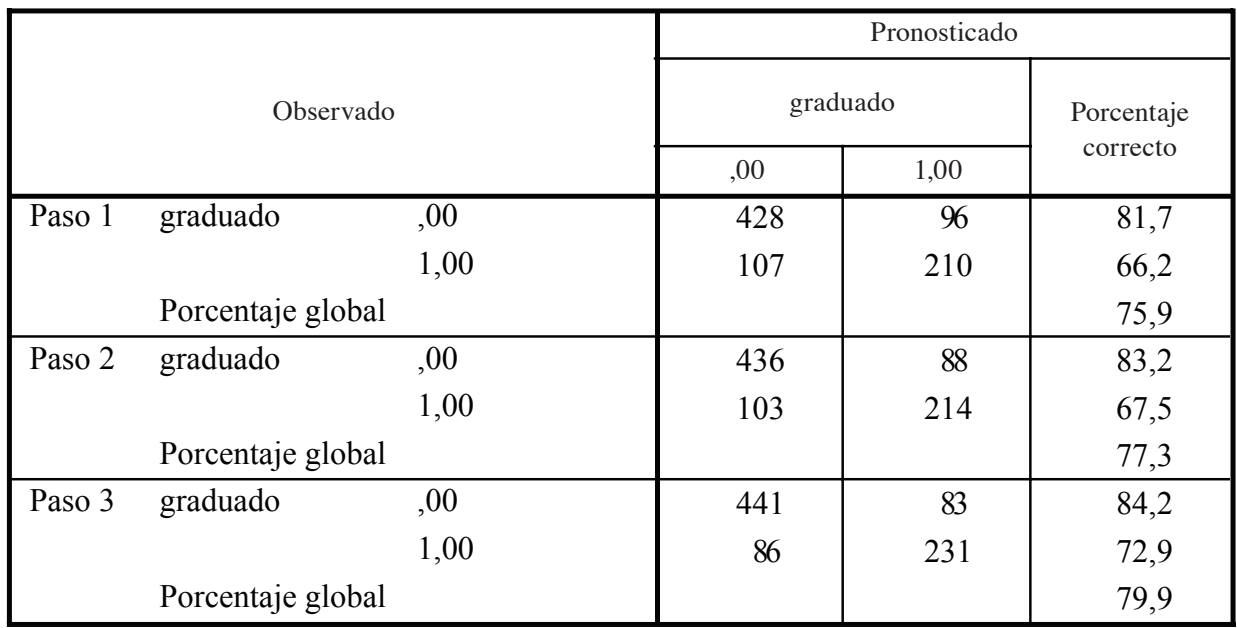

a. El valor de corte es ,500. 
Tabla 9

Variables in the Equation

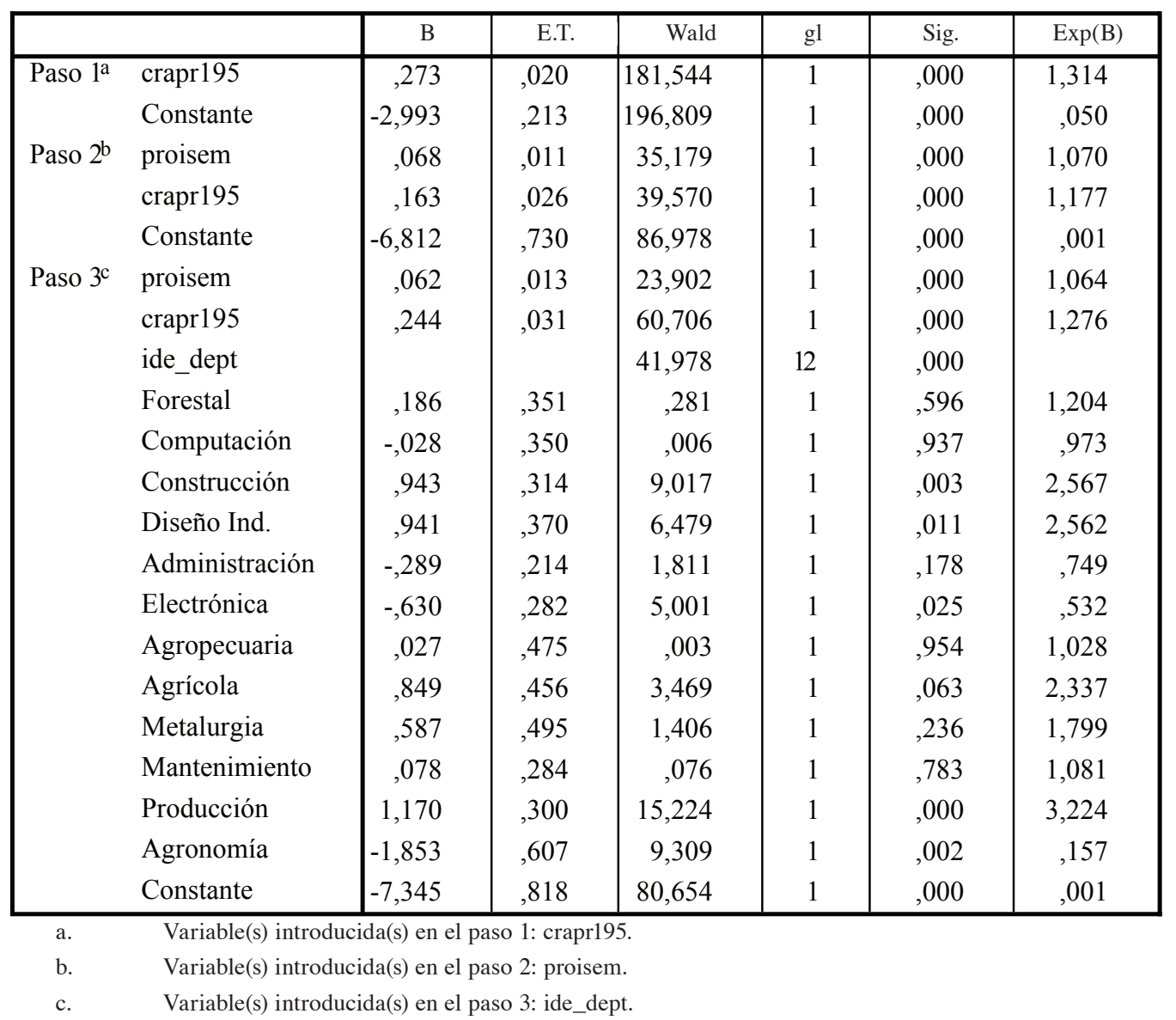

de detección temprana de estudiantes en riesgo académico tendríamos un $27,1 \%$ de falsos negativos y un $15,8 \%$ de falsos positivos.

Las afirmaciones anteriores, sin embargo, deben tomarse como una aproximación. Ya se anotó que la población de estudiantes del Instituto ha venido variando. Las tasas de graduación para la cohorte de 1995 son superiores a las de la cohorte de 1990. La proporción de mujeres se ha incrementado. La proporción de estudiantes provenientes de colegios privados se ha incrementado. Es probable que estas tendencias sigan manifestándose actualmente y las cohortes más recientes muestren resultados diferentes a las de la cohorte de 1995.

La ecuación para clasificar a los estudiantes como potenciales graduados o no graduados se deriva de la Tabla 9 'Variables en la ecuación'. Probabilidades inferiores a ,5 se clasifican como "No Graduado", probabilidades superiores a ,5 se clasifican como "Graduado".

Probabilidad $=1 / 1+e^{-z}$

Donde $\boldsymbol{e}$ es la base de los logaritmos naturales

$\mathbf{- z}=-(-7.345+$ proisem * .062 + crapr195

$* .244+$ Agropecuaria * $.027+$ administración * -.289 + Agronomía * -1.853 
+ Computación * -.028 + Construcción

*.943 + Diseño * .941 + Electrónica * $.630+$ Forestal * .186 + Agrícola * .849+ Metalurgia * .587+ Mantenimiento * .078 + Producción * 1,17).

Para efectos prácticos las escuelas tienen valor de 1 sólo en una de las doce variables y cero en las otras (con excepción de Seguridad Laboral e Higiene Ambiental), de modo que para ellas la ecuación se simplifica de doce coeficientes a uno.

Por ejemplo, el estudiante $\mathrm{X}$ de la Escuela de Electrónica obtuvo un promedio de 83,13 y aprobó 15 créditos durante el primer semestre de 1995. Para este estudiante la ecuación $1 / 1+e^{-z}$

donde $z=-7.345+83,13 * .062+15 * .244$ $-0,63$

resulta en una probabilidad de 0.6982 de graduarse. Este estudiante efectivamente se graduó en setiembre del año 2000.

Para el estudiante Y de la Escuela de Electrónica, quien obtuvo un promedio de 67,5 y aprobó 8 créditos durante el primer semestre de 1995, la probabilidad de graduarse producto de aplicar la ecuación es 0,137. Este estudiante desertó el segundo semestre del año 2000.

Véanse algunos promedios a modo de ilustración de las diferencias entre graduados y no graduados:

\begin{tabular}{lcc}
\hline & Graduados & $\begin{array}{c}\text { No- } \\
\text { Graduados }\end{array}$ \\
\hline $\begin{array}{l}\text { Promedio } \\
1^{\circ} \text { semestre: }\end{array}$ & 76,86 & 60,34 \\
$\begin{array}{l}\text { Créditos aprobados } \\
1^{\circ} \text { semestre: }\end{array}$ & 11,92 & \\
$\begin{array}{l}\text { Créditos aprobados / } \\
\text { cursados 1-95 }\end{array}$ &, 88 & \\
$\begin{array}{l}\text { Créditos aprobados / } \\
\text { matriculados 1-95 }\end{array}$ &, 84 &, 48 \\
\hline
\end{tabular}

Reiteramos que la clasificación no es perfecta. Para esta cohorte aplicar la ecuación redunda en un 79,9\% de clasificaciones correctas y $20,1 \%$ de clasificaciones erróneas. La ecuación, sin embargo, se convierte en un instrumento para estimar la probabilidad de graduarse de un estudiante. En particular, es un instrumento para determinar, a partir de los resultados obtenidos en el primer semestre, quiénes son los estudiantes en mayor riesgo de ver convertida en fracaso su experiencia académica en el ITCR y partir de esto orientar los servicios de la Vicerrectoría de Vida Estudiantil y Servicios Académicos.

\section{Algunos hallazgos de esta indagación}

1. Las variables asociadas a Puntaje de Admisión tienen escaso o ningún poder predictivo sobre los indicadores de rendimiento académico con que se operó en esta investigación.

2. Los tipos de jornada (diurna, nocturna), financiamiento (oficial, semioficial, privado), modalidad académica (académico, técnico, científico), del colegio de procedencia, así como la procedencia geográfica (Dentro o fuera de la Gran Área Metropolitana), no tienen poder predictivo sobre indicadores de corto o largo plazo del rendimiento académico.

3. Las mujeres presentan una Trayectoria distinta a la de los hombres, en particular en la categoría 'Graduado-No Graduado'. Para la cohorte de 1995, siete años después se había graduado el $47,8 \%$ de las mujeres y el $31,7 \%$ de los hombres.

4. El estudio tuvo como pretensión derivar ecuaciones para clasificar a los estudiantes en las distintas categorías de Trayectoria. Con ese propósito se aplicaron Análisis Discriminantes con indicadores de rendimiento académico en distintos momentos de la vida académica del estudiante. Los modelos derivados permitieron altos 
porcentajes de clasificaciones correctas para las categorías 'Desertó el primer semestre', 'Graduado' y en menor medida para 'Desertó después del segundo semestre'. Sin embargo para las categorías 'Desertó el segundo semestre' y 'Aún matriculados' el modelo resultó absolutamente inadecuado.

5. Se practicaron Análisis de Regresión Logística para la dicotomía 'Graduado -No Graduado' con indicadores de rendimiento académico del primer semestre. El modelo clasifica correctamente al 72,9\% de los Graduados y al $84,2 \%$ de los No Graduados. El modelo incluye las variables 'Número de créditos aprobados el primer semestre', 'Promedio en el primer semestre' y 'Escuela a que estuvo adscrito el estudiante ese semestre'. Este resulta el modelo a utilizar para clasificar a los estudiantes, con él se logra una clasificación correcta para el $79,9 \%$ de los casos.

\section{Notas}

1. Guillén Sánchez, E. y Chinchilla Brenes, S. Detección de estudiantes en riesgo académico. Cartago, ITCR, 2003.

2. Se incluye la condición $>0$ por cuanto el estudiante puede cursar una materia que, sin embargo, aparece registrada con nota $=0$, en este caso se considera que realmente no la cursó, la abandonó.

3. El conjunto de materias o créditos matriculados puede ser más amplio que el de cursados por cuanto el estudiante puede matricular y luego retirar.

\section{Referencias bibliográficas}

Bourdie, P. y Passeron, J.C. La reproducción, elementos para una teoría del sistema de enseñanza. Barcelona: Editorial Laia. 1977.
Clarke, D.C., "Easing the high school to college transition for rural learning disabled and other at-risk college students: a three credit course can make a difference". Paper presented at the International Conference of the Learning Disabilities Association. Atlanta. 1992.

Cohen, J. \& Cohen P. Applied multiple regression/correlation analysis for the behavioral sciences. New Jersey: Lawrence Erlbaum Associates Inc. 1983.

CONARE. Aspectos relacionados con el rendimiento académico de los estudiantes que ingresaron a las instituciones de educación superior universitaria estatal en 1990. San José: Costa Rica: Publicaciones CONAREOPES. 2000.

CONARE. Características sociodemográficas de los estudiantes de las universidades estatales 1996. San José, Costa Rica: Publicaciones CONARE-OPES. 1997.

Colorado Commission on Higher Education. Persistence and Completion Rates: Colorado Public Higher Education, Fall 1986 through Fall 1990. Colorado: Commission on Higher Education. 1991.

Dale, P.M. A successful college retention program. Purdue University Indiana, Estados Unidos de América: Horizons Program. 1995.

Grevatt, W.K., "Student success program". Mohawk College of Applied Arts and Technology. Ontario, Estados Unidos de América. 1992.

Guillén S., E. "Comparación resultados estudio CONARE 1996 y encuesta CONARE 2000". Documento de 
trabajo para la Comisión Índice Socioeconómico. Cartago: Instituto Tecnológico de Costa Rica. 2001.

Guillén S., E. Validez predictiva del Puntaje de Admisión y sus componentes, 19941998. Cartago: Instituto Tecnológico de Costa Rica. 1999.

Huesman, R.L. and others. "Identifying students at risk: utilizing traditional an non-traditional data sources". Albuquerque, New México: Paper presented at the Annual Forum of the Association for Institutional Research. 1996.

Illinois State Board of Higher Education. Retention, graduation and time-todegree of baccalaureate students at public universities. Illinois: Illinois State Board of Higher Education. 1996.

Kerbo, H.R. Estratificación social y desigualdad, el conflicto de clases en perspectiva histórica y comparada. España: McGraw-Hill. 1998.

Kezar, A. "Summer bridge programs: supporting all students". Eric Clearinghouse on Higher Education. Washington DC: George Washington University. 2000.

New York State Education Department, Bureau of Higher Education Opportunity Programs. Higher Education Opportunity Program Annual Report, 1992-1993. New York: HEOP Works, New York State Education Department. 1993.
Oregon State System of Higher Education. The long and winding road: retention, attrition, and graduation of OSSHE freshman entering 1986-87. A report to the Oregon State Board of Higher Education. Oregon: Oregon State System of Higher Education. 1994.

Ramist, L. "Predictive Validity of the ATP Tests". En The College Board Technical Handbook for the Scholastic Aptitude Test and Achievement Test. College Entrance Examination Board. NewYork: T.F. Editor. 1984.

Siegel, S., Estadística no paramétrica aplicada a las ciencias de la conducta. México, D.F.: Biblioteca Técnica de Psicología. 1985.

Starke, M.C. "Retention, bonding, and academic achievement: effectiveness of the College Seminar in promoting college success". Paper presented at the Annual Freshman Year Experience National Conference. Columbia, South Caroline. 1994.

University System of Georgia. Student Retention an Graduation: University System of Georgia. Georgia, Atlanta: Office of Research and Planning. 1994.

Wilkie, C. Statewide survey of developmental education in Pennsylvania. Trends in developmental education: research and practice. Pennsylvania: Pennsylvania Association of Developmental Educators. 1994. 